\title{
Co-existent Acquired Haemophilia and Lupus Anticoagulant. A Thorny Issue
}

\author{
Paul R. J. Ames ${ }^{1} \cdot$ Daniel Montero $^{1} \cdot$ Jeremy Archer $^{1}$
}

Received: 13 November 2014 / Accepted: 9 July 2015/Published online: 22 July 2015

(C) Indian Society of Haematology \& Transfusion Medicine 2015

\section{Dear Sir}

We read with interest the case of a 69 year old lady who presented clinically with bleeding and ecchimoses [1]. Investigations revealed a prolonged activated partial thromboplastin time (aPTT) at $110.2 \mathrm{~s}$ that corrected by $54 \%$ with normal plasma though we are not told to what extent a dilute Russel viper venom time (DRVVT) was prolonged and corrected with hexagonal phospholipids. A factor VIII level was at $04 \%$ (do the authors mean 0.4 or $4.0 \%$ ?) and anti-factor VIII level (Bethesda assay) of $08 \%$ (do the authors mean 0.8 or $8.0 \%$ ?) with Table 1 showing a complex inhibitor behaviour. The authors have not quoted the thromboplastin used for their aPTT: (1) a lupus insensitive reagent would have been helpful; (2) factor sensitivity to different thromboplastins modulates the correction of the mixing study. In the presence of auto anti-factor VIII antibodies the Bethesda assay may present with a type II inhibitor pattern but LA may interfere with this assay [2].

In the scenario given by the authors a chromogenic FVIII should have been done as well as a FVIII inhibitor measured by immune assay though LA could still interfere with the latter. Likewise, the measurement of anticardiolipin or antibeta-2-glycoprotein-1 antibodies may have better supported the presence of a LA the evidence for which relies on an undisclosed DRVVT [2]. However, a FVIII concentration below $0.15 \mathrm{IU} / \mathrm{mL}$ may influence the DRVVT result according to the sensitivity of reagents.
While the good clinical response to recombinant factor VII and immune suppression are in keeping with and acquired factor VIII inhibitor, the laboratory diagnosis of factor VIII is poorly supported and that of LA largely inadequate. LA tests based on direct prothrombin activation such as the Textarin/Ecarin [3] or the Taipan/Ecarin ratios [4] are more useful in the presence of factor VIII inhibitor, though not officially incorporated in the LA guidelines [5].

\section{References}

1. Gupta D, Chatterjee T, Sharma A, Ganguli P, Das S, Sharma S (2014) Rare case of acquired haemophilia and lupus anticoagulant. Indian J Hematol Blood Transfus 30:197-200

2. Ames PR, Graf M, Archer J, Scarpato N, Iannaccone L. Prolonged activated partial thromboplastin time: difficulties in discriminating coexistent factor VIII inhibitor and lupus anticoagulant. Clin Appl Thromb Hemost 2014. doi: 10.1177/1076029614541516

3. Triplett DA, Stocker KF, Unger GA, Barna LK (1993) The Textarin/Ecarin ratio: a confirmatory test for lupus anticoagulants. Thromb Haemost 70:925-931

4. Moore GW, Smith MP, Savidge GF (2003) The Ecarin time is an improved confirmatory test for the Taipan snake venom time in warfarinized patients with lupus anticoagulants. Blood Coagul Fibrinolysis 14:307-312

5. Brandt JT, Barna LK, Triplett DA (1995) Laboratory identification of lupus anticoagulants: results of the second international workshop for identification of lupus anticoagulants. On behalf of the subcommittee on lupus anticoagulants/antiphospholipid antibodies of the ISTH. Thromb Haemost 74:1597-1603
Paul R. J. Ames

paxmes@aol.com

1 Haemostasis \& Thrombosis Centre, St George's Hospital, Blackshaw Road, London, UK 